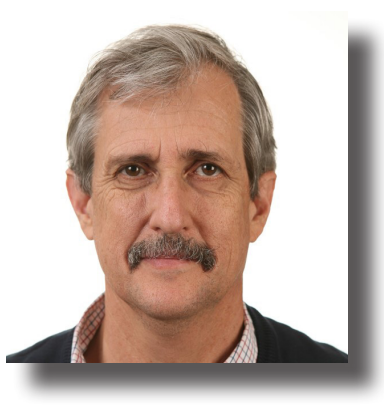

\title{
ABORDAJES CONCEPTUALES DEL TERRITORIO EN PERSPECTIVA LATINOAMERICANA
}

\author{
PhD. MARIO SAMPER KUTSCHBACH \\ mario.samper@gmail.com
} Investigador independiente y consultor de Comisión Económica para América Latina CEPAL Docente del Doctorado en Ciencias del Desarrollo Humano, UNAH ORCID:0000-0001-6594-9434

DOI: $10.5377 /$ rpdd.v6i1.12430

Recibido: agosto, 2021

Aceptado: septiembre, 2021

\section{RESUMEN}

E studio exploratorio e interpretativo de ciertos aspectos medulares del abordaje conceptual de los territorios en general, y en particular los territorios rurales o rural-urbanos, que se construyen y transforman a través de las interacciones de grupos asentados en determinados lugares entre sí, y con un medio natural progresivamente artificializado por la acción humana. Metodológicamente, se basa en discusiones comparadas anteriores de contribuciones sobre cuestiones relacionadas con el desarrollo territorial iberoamericano, con atención particular a Brasil, Colombia y América Central. Las conclusiones y propuestas conceptuales se apoyan en lecciones aprendidas sobre el concepto de territorio a partir de dichas experiencias, previamente documentadas o sistematizadas y contrastadas entre sí. Para identificar aprendizajes relevantes, el autor interactuó durante varios años con personas conocedoras de esas y otras experiencias latinoamericanas durante procesos internacionales, nacionales o territoriales de formación y gestión de conocimiento asociados a la Estrategia Centroamericana en Desarrollo Rural Territorial 2010-2030 (Ecadert), así como en foros virtuales y módulos de interaprendizaje latinoamericanos asociados al Sistema de Gestión Estratégica para el Desarrollo Territorial y la Agricultura Familiar -SiGET, y durante la preparación de un conjunto de publicaciones y recursos de gestión del conocimiento. 


\title{
PALABRAS CLAVE
}

Territorio -Desarrollo territorial - Ruralidad- Territorios rurales- América Latina - Brasil - Colombia - América Central.

\begin{abstract}
An interpretive, exploratory overview of certain key concepts regarding territories, and specifically rural and rural-urban areas, historically constructed by interactions among groups settled in certain places, and with a gradually transformed natural milieu. Methodologically, it is based on prior comparative discussions pertaining to Latin American territorial development, with special reference to Brazil, Colombia and Central America. Conclusions and proposals are based on lessons learned on the concept of territory in those and other documented cases in the region. The author interacted for several years with knowledgeable persons from various parts of Latin America during international, national and local training and knowledge management in the context of the Central American Area-based Rural Development Strategy 2010-2030 (Ecadert), as well as during on-line fora and shared learning workshops of the Area-based Development and Family Farming Strategic Management System - SiGET, and while preparing a set of related publications and knowledge management resources.
\end{abstract}

\section{KEYWORDS}

Territory -Territorial development - Rurality - Latin America - Brazil - Colombia - Central America

\section{INTRODUCCIÓN}

Este estudio, de índole exploratoria e interpretativa, aborda muy selectivamente aspectos relevantes de ciertos aportes latinoamericanos al abordaje conceptual de los territorios en general, y de los territorios rurales y rural-urbanos en particular. Complementariamente, alude a las territorialidades, relacionamientos e identidades compartidas y diferenciadas que se construyen y transforman a través de las interacciones de las personas o grupos, redes u organizaciones entre sí y con un medio natural progresivamente artificializado por la acción humana.

Primero se reconocen -por su relevancia para América Latina- los principales referentes europeos en cuanto al concepto de territorio que influyeron en países de esta región desde finales del siglo pasado, y se abordan los conceptos de territorio rural promovidos por la cooperación internacional en ella a partir de principios del siglo 
actual. Luego se hace referencia al concepto de territorio en general y de territorio rural en particular, en políticas y programas de algunos países latinoamericanos y mecanismos de integración, y se mencionan de manera muy breve y selectiva algunas contribuciones académicas latinoamericanas -principalmente geográficas y de ciertas ciencias sociales- relacionadas con la comprensión conceptual de los territorios, en especial rurales. Otras dos secciones se refieren, respectivamente a elaboraciones conceptuales de redes y centros de investigación para el desarrollo y la incidencia, ejemplificadas por uno de alcance latinoamericano, y a la maneras distintas de comprender su territorio de pueblos originarios y afrodescendientes, a través de uno específico, y se hace una breve referencia a la pertinencia de las perspectivas de género e intergeneracional acerca del territorio. Finalmente, se proponen algunos elementos para conceptualizar los territorios en general y los territorios rurales, urbanos y ruralurbanos, desde una comprensión alternativa de la ruralidad y de la relación campociudad.

La síntesis aquí presentada se apoya en discusiones comparadas anteriores de contribuciones sobre cuestiones conceptuales relacionadas con el desarrollo territorial iberoamericano, y en particular de Brasil, Colombia y América Central. Parte de un conjunto de aprendizajes derivados de esas y algunas otras experiencias latinoamericanas, contrastadas entre sí por el autor, en diálogo con personas conocedoras de ellas, durante procesos gestión del conocimiento para el desarrollo de los territorios rurales en el marco del Programa de Formación de Capacidades de la Estrategia Centroamericana en Desarrollo Rural Territorial 2010-2030 (Ecadert) e intercambios relacionados. Paralela y posteriormente, prosiguieron los intercambios y reflexiones comparads a partir de experiencias territoriales y político-institucionales en foros virtuales y módulos interaprendizaje del Sistema de Gestión Estratégica para el Desarrollo Territorial y la Agricultura Familiar (SiGET), con participantes de toda América Latina. También se nutre de la participación del autor en la producción de herramientas conceptuales y metodológicas, glosarios técnicos, publicaciones relacionadas y recursos virtuales, incluyendo fascículos del SiGET, Cuadernos de Trabajo sobre Inclusión, y el centro de recursos virtuales "Territorios y Desarrollos", en proceso de construcción.

Por otra parte, se retoma y desarrolla algunos elementos de dos presentaciones del autor en el foro virtual Debate Contemporáneo sobre las Ciencias del Desarrollo Humano: "Algunas elaboraciones conceptuales sobre cuestiones territoriales en América Latina", y "Reconceptualización y medición alternativa de las ruralidades latinoamericanas". Las ideas y perspectivas se presentan aquí de manera selectiva y sucinta por la naturaleza y finalidad del número especial de esta revista, dedicado a dicho foro. Lejos de intentar un abordaje exhaustivo, se sugieren algunos elementos conceptuales y autores o autoras pertinentes. Las referencias son igualmente 
selectivas, priorizando aportes especialmente significativos e influyentes; reflexiones comparadas y planteamientos de índole general atinentes a las cuestiones abordadas. Se remite a las personas lectoras a los enlaces a medios virtuales pertinentes y a la literatura académica u otra documentación referenciada en los trabajos citados.

\section{Referentes europeos en diálogo con perspectivas latinoamericanas}

En Europa -aunque no sólo allí- las ciencias naturales y sociales aportaron nuevas conceptualizaciones en torno al territorio, asociadas en parte a nuevas políticas rurales en la Unión Europea desde finales del siglo pasado. (Sarraceno, 2007) La ecología ha contribuido elementos conceptuales relacionados con las biorregiones y los ecosistemas, trascendiendo el concepto etológico de territorios o territorialidades animales, mientras que la agroecología ha desarrollado el concepto de agroecosistemas, y la agronomía, especialmente francesa, el análisis de los sistemas de producción locales y sistemas agrarios regionales, así como la conceptualización de los sistemas agrícolas o agroalimentarios localizados. Diversas ciencias sociales han explorado el papel de las relaciones de poder, de las redes sociales o de las vivencias e identidades compartidas en la conformación de territorios, y se ha concebido al territorio como espacio social, tanto presente como pretérito y prospectivo.

Ciencias híbridas como la geografía han combinado estudios territoriales a diversas escalas, incluyendo los paisajes locales y las regiones o microrregiones, con reflexiones, debates y elaboraciones conceptuales pertinentes e influyentes en torno a las relaciones entre territorio y espacio. Disciplinas humanistas como la filosofía, la fenomenología, la semiótica y la epistemología han indagado acerca de los espacios vividos y percibidos, así como la construcción y deconstrucción del territorio y la territorialidad. La comprensión de los territorios en cuanto sistemas sociogeográficos o socionaturales se ha enriquecido con aportes del pensamiento sistémico y del pensamiento complejo. Han surgido abordajes inter o transdisciplinarios del territorio en general y de los territorios urbanos o rurales en particular, como también de las territorialidades, y se ha llegado a postular una teoría y una ciencia del territorio. (Pacquot, 2012; Capel, 2016; Péaud, 2016).

En estos y otros campos de conocimiento, de investigación y de reflexión acerca de la conceptualización del territorio hubo y sigue habiendo aportes pioneros e influyentes desde el Viejo Mundo, diálogos trasatlánticos y elaboraciones innovadoras en países latinoamericanos, a la luz de sus propias realidades, tradiciones intelectuales, dinámicas sociales e institucionalidades. 
Tres antecedentes europeos especialmente significativos en lo atinente a la comprensión del territorio y lo territorial en tiempos recientes, desde el ángulo de las políticas públicas, fueron referentes para América Latina al iniciar e impulsar programas de desarrollo rural con enfoque territorial:

-los denominados “distritos industriales" de inspiración Marshalliana y con precedentes en la industria textilera inglesa, redescubiertos y replanteados conceptualmente y en términos de políticas públicas en Italia, también fueron relevantes en España, y tanto las experiencias como las conceptualizaciones europeas de conglomerados productivos de base territorial fueron estudiadas desde la óptica del desarrollo también en Latinoamérica (Sforzi, 1990; Quintar y Gatto, 1992; Becattini, 2002; Boix, 2008; Brunelli, 2014);

- los pays franceses - urbanos, peri-urbanos, rurales, o mixtos-, elegidos y propuestos por los actores locales como territorios-proyecto supramunicipales con capacidad prospectiva y de reflexión estratégica, que reunían a varias municipalidades bajo diversas modalidades jurídicas, fueron reconocidos como entes asociativos capaces de entablar relaciones contractuales con la institucionalidad pública desde la década de 1970 e inscritos en una gobernanza multinivel para la concertación y planificación territorial, y han evolucionado desde 2014 hacia la conformación de "Polos de Equilibrio Territorial y Rural" (PETR) con miras a la cooperación entre los territorios rurales y las ciudades pequeñas o medianas (Lollier, 1999; Doré, 2011; APFP, 2012; Vanier, 2016);

- las comarcas u otras instancias supramunicipales españolas con sus Grupos de Acción Local (GAL) o Grupos de Desarrollo Rural (GDR), constituidos con el doble propósito de acceder a fondos europeos de inversión para revitalizar áreas rurales, y de impulsar estrategias e iniciativas de desarrollo, generando proyectos de territorio o "territorios-proyecto". (MAPA, 2003; Caballero y otros, 2011)

Las maneras institucionales de abordar el territorio y la territorialidad en iniciativas de desarrollo se expresaron en el programa LEADER de la Unión Europea, a partir de 1991. En lo atinente al concepto de territorio, se transitó desde las referencias anteriores a regiones, zonas o áreas rurales en los primeros documentos comunitarios enfocados en el desarrollo rural (Comisión Europea, 1988) hacia una definición operativa de los territorios de actuación de este programa:

Este territorio LEADER se entiende que corresponde a una determinada identidad natural y/o cultural, presentando unos rasgos socioeconómicos relativamente homogéneos, sin que necesariamente coincida con una división administrativa. El territorio no puede ser ni muy pequeño (ausencia de "masa crítica", costos operativos 
muy elevados) ni muy grande (ausencia de homogeneidad), Idealmente debe estar dotado de identidad local; los habitantes tienen que reconocerse como formando parte del mismo y los foráneos deben poder identificarlo. (Rosell, 2002, p. 38).

Los principios orientadores, conceptos básicos y abordajes españoles de lo territorial, en el marco de ese programa, se proyectaron hacia América Latina por diversas vías, e influyeron en el abordaje institucional de territorios supramunicipales, con elementos identitarios y escalas espaciales que inicialmente se asimilaron a microrregiones en varios países de la región. Una de estas vías fue la de los programas de formación e intercambios principalmente en España, en los cuales participaron responsables político-institucionales y técnicos de varios países latinoamericanos desde principios del siglo actual. Otra vía fue la realización de proyectos que transfirieron elementos del abordaje conceptual y metodológica del programa LEADER en experiencias piloto en territorios latinoamericanos, principalmente el proyecto Experiencias piloto de desarrollo local rural en América Latina (EXPIDER) ${ }^{1}$, y años después el proyecto Políticas innovadoras para el desarrollo de los territorios rurales en América Latina (PIDERAL)². También se aplicó la metodología LEADER en territorios específicos de Colombia y México, entre otros países latinoamericanos (Rey, 2009; De los Ríos-Carmenado y otros, 2011). Los resultados mixtos por las diferentes condiciones de la Unión Europea y América Latina en múltiples facetas de la institucionalidad pública y las organizaciones de sociedad civil, los procesos de financiación de iniciativas y la continuidad de los procesos e inversiones. (Sumpsi, 2006) Por otra parte, elementos conceptuales y metodológicos del programa LEADER se incorporaron en políticas públicas latinoamericanas, en países como Brasil y Argentina (Ghesti, 2014).

\section{Conceptos de territorio rural promovidos por la cooperación internacional en América Latina}

La conceptualización del territorio por parte de la cooperación internacional tuvo expresiones afines aunque diferenciadas en organizaciones multilaterales y agencias de cooperación técnica internacional en América Latina. El Grupo Interagencial de Desarrollo Rural en América Latina y el Caribe (GIADR) reunió a partir del año 2000 a varios organismos internacionales para coordinar acciones de cooperación técnica y financiera para el desarrollo rural en América Latina ${ }^{3}$.

\footnotetext{
1 Para un balance de lecciones derivadas de experiencias piloto promovidas por EXPIDER en Ecuador, Bolivia y Honduras entre 2003 y 2005, cf. Sumpsi, 2006 a).

2 PIDERAL se ejecutó en Ecuador, Perú, Costa Rica y República Dominicana entre 2012 y 2014.

3 Inicialmente el GIADR lo conformaron el BID, Cepal, FAO, FIDA, GTZ e IICA, y luego se sumaron la AID y AECID.
} 
Algunas de las agencias participantes en el GIADR generaron y promovieron, en años subsiguientes, conceptos afines o complementarios de territorio o de territorio rural, con ciertas diferencias, a través de sus contrapartes institucionales en los países, como también de proyectos en territorios o programas de capacitación.

El Instituto Interamericano de Cooperación para la Agricultura (IICA) proponía como definición en 2006 :

Los territorios rurales son ámbitos geográficos con una historia propia y una base común de recursos naturales, donde ocurre la actividad agrícola y se dan relaciones socio-culturales, técnico-económicas y político-institucionales que vinculan a los actores del agro entre sí, con su ambiente natural, con otras actividades no agrícolas y con núcleos urbanos. (IICA, 2006, p. xiii).

En un balance de experiencias latinoamericanas en desarrollo de territorios rurales en América Latina y el Caribe, realizado por la Agencia de Cooperación Internacional de Japón (JICA) en 2012, se proponía una definición del territorio como

"la construcción social donde las instituciones públicas, actores sociales y agentes económicos construyen sobre un espacio geográfico, una estrategia común de desarrollo a partir de reconocerse con una identidad propia. (...) es concebido como una unidad espacial, compuesta por un tejido social particular, que se asienta sobre recursos naturales y que genera riqueza y renta a partir de una organización dada de la producción, intercambio y consumo, regulada por instituciones con competencia en la materia y mediada por organizaciones de la sociedad civil que opera en dicha unidad espacial. (JICA, 2012, p. 16)"

Al revisar retrospectivamente los principales planteamientos sobre desarrollo territorial rural en América Latina y el Caribe, el Representante Regional de FAO y uno de los más lúcidos estudiosos del tema en la región encontraron que uno de sus elementos comunes era la "definición del territorio como un espacio socialmente construido y, por ende, como un conjunto de estructuras, instituciones y actores, más que como una geografía con determinadas condiciones físico-biológicas" (Berdegué y Favareto, p. 4). Y ciertamente, parece haber un relativo consenso al respecto tanto en las agencias de cooperación como, en grado variable, entre sus contrapartes institucionales en los países.

La Comisión Económica para América Latina (Cepal ) y su Instituto Latinoamericano y del Caribe de Planificación Económica y Social (Ilpes) han entendido al territorio como "un sistema de interacciones sociales históricamente estructuradas y en constante evolución" (Cepal, 2010, p. 132), e Ilpes concibe al 
territorio como una construcción social en la cual tanto las dimensiones físicas o materiales como aquellas subjetivas o culturales, que caracterizan a un territorio en un momento histórico dado, son producto de un complejo y evolutivo sistema de interacciones sociales que produce, reproduce y transforma los lugares específicos y su vinculación o interacción con otros lugares". (Riffo, 2013, p. 38)

En un estudio reciente sobre planificación para el desarrollo territorial en Latinoamérica, la Cepal reconoció el carácter polisémico del concepto de territorio, y lo definió para propósitos de dicho documento como "una comunidad humana con sentido de apropiación y pertenencia hacia un espacio natural y social específico (Cepal, 2019, p. 21).

El Programa de Naciones Unidas para el Desarrollo (PNUD), en el marco del desarrollo económico territorial, considera que el territorio no solo es un espacio geográfico, sino una construcción social dinámica que se despliega a través de redes, instituciones y capital social. Es el resultado de un proceso animado por sus actores económicos, sociales e institucionales (...). La diversidad social, cultural y organizativa obliga a pensar en el territorio como un actor del desarrollo, un espacio vivo. Sus recursos y activos comprenden los elementos endógenos (...) además de lo que la población posee, sabe o hace, y que es posible fortalecer con el aprendizaje y la innovación (...) (PNUD, 2013, p. 5).

Los conceptos y definiciones antedichos tienen algunos denominadores comunes, como la naturaleza socialmente construida de los territorios y su relación con determinados espacios físico-geográficos en los cuales interactúan determinados actores sociales, económicos e institucionales. Por otra parte, se reconoce que el término "territorio" tiene múltiples significados, algunos de ellos relacionados con identidades colectivas y sentidos de pertenencia, con ciertos tipos de actividades económicas, o con redes y tejido social.

Las agencias más relacionadas con el agro y el campo enfocan su atención en los territorios rurales, y proponen definiciones de éstos, o alternativamente determinados rasgos indicativos de ruralidad, como la relevancia de los recursos o de actividades agropecuarias. No se encuentra claramente, en las definiciones antedichas, una construcción conceptual que, de manera integral e integrada, ofrezca un concepto general de territorio y conceptos derivados, a la vez que diferenciados, de territorio rural o de territorio urbano, como tampoco de territorio rural-urbano. 


\section{Conceptos de territorio en las políticas públicas latinoamericanas}

Las definiciones explícitas o conceptos implícitos de "territorio" o "territorio rural" en normas legales o documentos programáticos oficiales son ilustrativas de las maneras de entender la naturaleza y función de los territorios desde la perspectiva de la institucionalidad pública. Aquí se darán solamente algunos ejemplos ilustrativos de cuatro países: Colombia, México, Brasil y Costa Rica, así como dos entidades supranacionales: el Sistema de la Integración Centroamericana (SICA) y la Comunidad Andina de Naciones (CAN).

En Colombia ha venido decantándose, desde la Constitución de 1991, un conjunto entrelazado y cambiante de conceptos de territorio, además de los usuales en América Latina referentes al país en su conjunto y a sus entidades políticoadministrativas. En esta constitución colombiana, innovadora en muchos sentidos, se dio pleno reconocimiento jurídico como entidades territoriales con un grado considerable de autonomía a los territorios indígenas. Se previó la opción de que dos o más departamentos se constituyan en regiones administrativas y de planificación, con personería jurídica, autonomía y recursos propios para impulsar "el desarrollo económico y social del respectivo territorio". (art. 306) También se normó la conformación de provincias, por iniciativa ciudadana o de las autoridades locales, "con municipios o territorios indígenas circunvecinos, pertenecientes a un mismo departamento." (art. 321) Y mediante un artículo transitorio en 2009 se normó el establecimiento de una serie de territorios conformados por ecorregiones con un "régimen especial en lo económico, lo político, lo social y lo administrativo (...) con el objetivo de reducir los desequilibrios que frente a su desarrollo existen con el resto del país." ( nuevo artículo 14).

Para el Departamento Nacional de Planeación (DNP) de Colombia, que incorpora en su quehacer elementos conceptuales y metodológicos de un abordaje territorial multi-escalar, al referirse a esquemas asociativos de entidades territoriales para la gestión del desarrollo de un territorio que normalmente trasciende los límites de cada entidad territorial político-administrativa,

Las asociaciones hay que considerarlas bajo un enfoque de desarrollo territorial, que sitúa al territorio como sujeto y protagonista de los esfuerzos de desarrollo y gobernanza en el ámbito regional y local, bajo el liderazgo de las autoridades territoriales.

(...) La responsabilidad territorial es un espacio socio-político para la práctica territorial o construcción social de territorios en el ámbito de la responsabilidad de los gobiernos, las instituciones y los ciudadanos. (DNP, 2013, pp. 9 y 15) 
En el acuerdo entre el Estado colombiano y las Fuerzas Armadas Revolucionarias de Colombia (FARC-EP), firmado en 2016 y avalado legislativamente el año siguiente, se hace referencia en singular al territorio nacional y en plural a los territorios y a las regiones de las cuales forman parte, con énfasis en "los territorios más afectados por el conflicto". El capítulo sobre la Reforma Rural Integral en este acuerdo, que incorpora de manera explícita un enfoque territorial, concibe el territorio rural como un escenario socio-histórico con diversidad social y cultural, en el que las comunidades -hombres y mujeres- desempeñan un papel protagónico en la definición del mejoramiento de sus condiciones de vida y en la definición del desarrollo del país dentro de una visión de integración urbano-rural (Presidencia de la República y Estado Mayor Central de las FARC-EP, 2016, cap. 1)

Otra política colombiana innovadora en el contexto latinoamericano es el conjunto de lineamientos estratégicos para la agricultura campesina, familiar y comunitaria (ACFC), que reconoció de manera explícita la territorialidad inherente a la ACFC, así como su relación co-evolutiva con las territorialidades, y la necesidad de fortalecer los sistemas territoriales de ACFC. En dichos lineamientos, adoptados en 2017, se definió al territorio como:

Espacio geográfico en el que una persona, grupo de personas, institución, o Estado ejercen control y dominio. En tanto producto social e histórico, el territorio puede ser de carácter ur- bano, rural, marítimo, insular o aéreo dotado de una determinada base de bienes naturales comunes, ciertas formas de producción, consumo e intercambio, así como bienes y servicios públicos y una red de instituciones y formas de organización que se encargan de darle cohe- sión a la totalidad de los elementos constitutivos. (p. 57)

Hay, pues, más de un concepto de territorio en las normativas constitucionales e institucionales y lineamientos de políticas colombianas, incluyendo esquemas político-administrativos o asociativos, un abordaje multiescalar y otro que remite directamente al ejercicio del control sobre un espacio geográfico. Por otra parte, un instrumento producto de negociaciones para poner fin al conflicto armado interno define al territorio rural como una escenario social históricamente construido y culturalmente diverso, con protagonismo de las comunidades en el desarrollo local y nacional, y propone una visión en la cual se enfatizan los vínculos rural-urbanos.

En México, la Ley de Desarrollo Rural Sustentable, aprobada por el Congreso federal en 2001, legislación pionera en América Latina, no elabora un concepto general de territorio, pero sí se refiere a los Distritos de Desarrollo Rural, indicando que serán la base de la organización territorial y administrativa de las dependencias de la Administración Pública Federal y Descentralizada, para la realización de los 
programas operativos de la Administración Pública Federal que participan en el en el Programa Especial Concurrente y los Programas Sectoriales que de él derivan, así como con los gobiernos de las entidades federativas y municipales y para la concertación con las organizaciones de productores y los sectores social y privado. (...) contarán con un Consejo Distrital formado por representantes de los Consejos Municipales. La Secretaría definirá, con la participación de los Consejos Estatales la demarcación territorial de los Distritos de Desarrollo Rural y la ubicación de los centros de apoyo al desarrollo rural sustentable, con los que contará cada Distrito de Desarrollo Rural, procurando la coincidencia con las cuentas hídricas. (Congreso Mexicano, 2001, art. 29).

Los Distritos de Desarrollo Rural eran, pues, un mecanismo para la territorialización de programas federales y estaduales, con participación de representantes de los Consejos Municipales y mecanismos de concertación públicoprivados. Su demarcación, "como base geográfica para la cobertura territorial de atención a los productores del sector rural" y de programas productivos o servicios especializados (art. 24.V) debía ajustarse lo más posible a cuencas hidrográficas, y correspondía a la Secretaría de Agricultura, Ganadería, Desarrollo Rural, Pesca y Alimentación. Diversos programas federales y algunos estaduales abordaban distintas facetas del desarrollo de los territorios rurales, sin una conceptualización clara o definición común de los mismos hacia 2009, cuando se realizó un inventario de políticas y programas de desarrollo territorial rural en el país. (Soberanes y Burgin, 2009).

En Brasil, un Documento Institucional de la Secretaría de Desarrollo Territorial del Ministerio de Desarrollo Agrario (MDA/SDT) ofreció como punto de partida, en 2003, un concepto general de territorio. El primero correspondía a una suerte de "recorte espacial" urbano-rural:

Un espacio físico, geográficamente definido, generalmente continuo, que comprende ciudades y campos, caracterizado por criterios multidimensionales, tales como el ambiente, la economía, la sociedad, la cultura, la política y las instituciones, y una población con grupos sociales relativamente distintivos, que se relacionan interna y externamente mediante procesos específicos, donde se puede distinguir uno o más elementos indicativos de identidad y cohesión social, cultural y Territorial ${ }^{4}$. 
Y un documento del Consejo Nacional de Desarrollo Sustentable (Condraf) en 2003 proponía un concepto derivado del anterior y enfocado en los territorios rurales:

Son los territorios en los cuales los criterios multidimensionales que los caracterizan, así como los elementos más destacados que facilitan la cohesión social, cultural y territorial, presentan, de manera explícita o implícita, la preponderancia de elementos "rurales". Estos territorios incluyen los espacios urbanizados que comprenden ciudades pequeñas o medianas, villas o poblados 5 .

En nota al pie se indica que dichos elementos rurales están asociados a un ambiente natural poco modificado o parcialmente transformado para actividades agro-silvo-pastoriles; baja densidad demográfica o población pequeña; basado en la economía primaria y sus encadenamientos secundarios o terciarios; hábitos culturales y tradiciones típicas del universo rural. Esta aclaración resuelve en parte la circularidad de la definición original de lo rural, aunque en lo atinente a la cultura es nuevamente circular.

En el programa Programa Nacional de Desenvolvimento Sustentável de Territórios Rurais (Pronat), conocido como Territorios de Identidad, se combinó la formulación de proyectos y planes de desarrollo en dichos territorios intermunicipales o microrregiones con rasgos identitarios y con un peso relevante de la agricultura familiar. En ellos se conformaron Colegiados Territoriales u otros órganos colegiados así como asociaciones intermunicipales denominadas Consórcios Intermunicipais de Segurança Alimentar e Desenvolvimento Local (Consads), como espacios de interlocución entre la institucionalidad pública y la sociedad civil para consolidar iniciativas territoriales. (Brito, 2017, p. 186)

Otro programa gubernamental brasileño denominado Promoção da Sustentabilidade de Espaços Sub-regionais (Promeso) se enfocó en mesorregiones diferenciadas por sus características culturales, socioeconómicas, políticas y ambientales, buscando potencializar sus activos tangibles e intangibles para reducir desigualdades sociales y regionales. Se enmarcó en la Política Nacional de Desarrollo Regional del Ministerio de la Integración Nacional, y buscó articular acciones institucionales, sin una participación social significativa en los foros establecidos por este programa. (Favareto, 2009) Así, se definió una escala territorial intermedia entre las macro y microrregiones, sin incorporar elementos conceptuales y metodológicos fundamentales del enfoque territorial.

5 Referências para um Programa Territorial de Desenvolvimento Rural Sustentável. CONDRAF, junio de 2003, p. 23, citado en da Rocha y Filippi, s.f., p. 7. Traducción libre del autor. 
Por su parte, la institucionalidad pública costarricense fue elaborando un marco conceptual para el abordaje de los territorios rurales y su desarrollo, partiendo de experiencias piloto del Programa de Desarrollo Rural del Ministerio de Agricultura (MAG), apoyado por el proyecto Expider, y continuando mediante la participación del país en la formulación e implementación inicial de la Ecadert, asociada a su vez al proceso de transformación institucional que dio origen al Instituto de Desarrollo Rural.

En la Política de Estado para el Sector Agroalimentario y el Desarrollo Rural Costarricense 2010-2021 (MAG, 2011) se incorporó la "gestión de los territorios rurales y agricultura familiar" como uno de sus cuatro ejes temáticos, y como área estratégica la "economía rural de los territorios". Estos últimos no se definieron en dicha política, pero se hizo referencia a la Ecadert en el marco de políticas y estrategias regionales.

En 2012, la Ley 9036 que transformó al Instituto de Desarrollo Agrario (IDA) en Instituto de Desarrollo Rural (Inder), con un claro enfoque territorial, definió al territorio rural como una unidad geográfica dedicada principalmente al desarrollo de actividades rurales, compuesta por un tejido social e institucional particular, asentada en una base de recursos naturales propios, con formas de organización, producción, consumo, intercambio y manifestaciones de identidad comunes.

(...) El Inder tomará como base de planificación y operación el territorio rural. Para fines operativos, el territorio lo conforman uno o varios cantones, o algunos de sus distritos, que presentan características comunes desde el punto de vista de su ecología, de sus actividades económicas, culturales, institucionales, políticas y de las modalidades de generación de ingresos de la población habitante en ellos.

Los territorios rurales son áreas que dependen económica y socialmente, de manera predominante, de las actividades derivadas de utilización de los suelos, las aguas y los bosques, traducido en el valor económico generado por ellos, incluyendo el empleo y las actividades relacionadas con comercio y prestación de servicios. (Asamblea, Legislativa, 2012, Ley 9036, Art. 9)

Una nueva política de Estado, centrada en el Desarrollo Rural Territorial, se aprobó en 2016, la cual incorpora como alternativa de desagregación regional los 27 territorios rurales establecidos hasta entonces por el Inder, y propone una priorización por necesidades básicas insatisfechas de su población. Para su definición se apoya, asimismo, en la norma legal que transformó al IDA en Inder: 
La Ley No 9036 establece el territorio rural como base de planificación y operación del desarrollo rural territorial. Un territorio se conforma con uno o varios cantones, o algunos de sus distritos, que presenten características comunes desde el punto de vista de su ecología, de sus actividades socio-económicas, culturales y político-institucionales. (Sepsa e Inder, 2016)

En la Estrategia Centroamericana de Desarrollo Rural Territorial 20102030 (Ecadert) el concepto de territorio se define primero a nivel general y luego en lo atinente a los territorios rurales, aunque la distinción entre ambos conceptos o definiciones no es del todo nítida:

En el marco del Desarrollo Rural Territorial, el territorio no es única ni principalmente un espacio físico-geográfico, sino que se trata de una construcción social. No sólo es el reflejo de una comunidad, sino que participa en la constitución de la misma y en la conformación de su identidad. El territorio es una expresión tangible de procesos históricos y un factor de continuidad, pero no es estático sino cambiante; por consiguiente, es también factor de transformación.

Desde la perspectiva de identidad cultural, el territorio puede incluso desplazarse geográficamente, como suele suceder cuando pueblos enteros se trasladan hacia otros lugares por diversas razones y reconstruyen sus modos de vida. También puede, a veces, ser discontinuo, cuando su identidad es fragmentada por circunstancias de diversa índole. El territorio es una instancia dinámica, que cambia constantemente.

En general, cada territorio rural forma un conjunto relativamente homogéneo desde el punto de vista de su geografía física, de sus condiciones económicas y de su organización social. Se observa en el territorio ciertos ecosistemas, estructuras de poder (social, económico, político, cultural y religioso), relaciones de parentesco y vecindad, formas de producción, relaciones laborales, procesos migratorios, modos de vida y patrones culturales, creencias y costumbres, arreglos institucionales, sistemas tecnológicos y formas de espiritualidad. (CAC, 2010, p. 17).

Un documento de trabajo de la Comunidad Andina de Naciones (CAN) sobre lineamientos para el desarrollo rural territorial de la CAN, presentado en la IV Reunión del Consejo de Ministros de Agricultura, se refiere a la "articulación y 
la armonización, en el territorio, de políticas, programas y proyectos, fundamentada en procesos participativos de actores sociales locales (pobladores) e instituciones públicas y privadas (...) con miras a contar con un procesos de transformación económica, social, cultural e institucional en un espacio rural determinado (...)." (CAN, 2013, p. 1) No se define el concepto de territorio, utilizado a lo largo del documento, pero se emplea como sinónimo de "área rural", y se propone priorizar determinados "territorios rurales" andinos por su menor desarrollo relativo.

Por lo antedicho, es claro que en la institucionalidad pública de los cuatro países y dos mecanismos de integración hay diferentes abordajes conceptuales de los territorios en general y de los territorios rurales en particular. Por otra parte, ciertos elementos tienden a reiterarse por una parte en las definiciones con mayor grado de generalidad, y se hace referencia a algunos elementos diferenciadores de los territorios rurales. Pero la institucionalidad pública tanto nacional como supranacional parece carecer, en esos casos, de un abordaje unificado en el cual se defina con claridad y consistencia conceptual al territorio en general y al territorio rural en particular, a partir de sus propias características actuales.

\section{Aproximaciones geográficas y científico sociales a los conceptos de territorio y territorialidad en América Latina}

Las contribuciones de la academia a la comprensión del territorio, y en especial de los territorios rurales en América Latina, son múltiples, diversas y enriquecedoras tanto en el plano teórico como en la operacionalización del concepto, y en la reflexión crítica o propositiva en torno a sus abordajes por parte de la institucionalidad pública y la cooperación internacional. Como referencia general, se remite a las personas lectoras a las síntesis interpretativas compartidas en cuatro documentos sobre aprendizajes latinoamericanos acerca de los principales tipos de elaboraciones conceptuales. En los referentes a Brasil, Colombia y Centroamérica se identifican líneas de trabajo y de discusión disciplinarias e interdisciplinarias, y se mencionan muy selectivamente ciertas conceptualizaciones relevantes, y en la visión de conjunto latinoamericana se destacan los aportes conceptuales derivados de la contrastación de experiencias territoriales o político-institucionales en estudios comparados y por parte de redes académicas nacionales y latinoamericanas (Samper y González, 2018 a y b; Samper, 2020 y 2021).

Sobre la cuestión del abordaje necesariamente interdisciplinario, y de ser posible también transdisciplinario, del desarrollo sustentable de los territorios rurales, 
se remite a la persona lectora al excelente ensayo de João Torrens publicado en este mismo volumen y eje temático. Sus cuatro ideas clave apuntan a la necesidad de un cambio de paradigma para abordar las múltiples crisis entrelazadas del mundo actual, así como las transformaciones recientes de la ruralidad, con nuevos conceptos y enfoques, agendas de investigación integradoras y redes o articulaciones innovadoras para la acción colectiva, tendiendo puentes entre disciplinas y forjando nuevos campos de conocimiento para impulsar dicho desarrollo. ${ }^{6}$

En lugar de ensayar una síntesis apretada de los múltiples campos del conocimiento que han abordado la cuestión del territorio en América Latina, se optó aquí por enfocar la atención principalmente en la Geografía, que por su naturaleza híbrida tiende puentes entre las ciencias naturales y sociales, por lo cual está excepcionalmente posicionada para aportar a la reflexión e indagación sobre territorios socionaturales. Su perspectiva es, además, inherentemente multiescalar, pues su mirada abarca desde el paisaje local y las microrregiones hasta las meso y macrorregiones, e incorpora -en diálogos con la Historia- la diacronía y periodización. Aquí se mencionan brevemente ciertos aportes de dos exponentes principales de la geografía brasileña de final y principio de siglo, pionera en este campo, para luego comentar muy brevemente ciertas conversaciones geográficas e interdisciplinarias sobre cuestiones relacionadas en Colombia y Centroamérica, y finalmente algunos planteamientos de índole más general.

Milton Almeida dos Santos, gran impulsor de la Geografía Crítica en Brasil, cuestionaba la separación entre los aspectos materiales y sociales del territorio, y afirmaba que la categoría de análisis pertinente no es el territorio en abstracto sino el territorio utilizado, habitado y transformado por la gente; que la cuestión del territorio debe ser abordada históricamente, constatando sus transformaciones en sucesivos momentos locales, nacionales y globales, con sus respectivos conceptos de territorio y territorialidad, y que es necesario enfocar el análisis en el espacio "trivial" de los geógrafos, que pertenece a todas las personas, instituciones y empresas -no sólo algunas- y lejos de ser particularmente económico, político o cultural, abarca múltiples facetas. (Santos, 2000) Este pensador geográfico introdujo también el concepto de "configuración territorial" formada por recursos naturales y creados, dispuestas como sistema, con interdependencias complejas entre lo natural y lo artificial. (Santos, 1996).

6 João Torrens, “Desarrollo Sostenible de los Territorios Rurales: desafíos de la interdisciplinariedad”, en este volumen. 
Para Santos, la vieja categoría de región se ve trascendida por nuevos recortes territoriales, que son:

Un resultado de la nueva construcción del espacio y del nuevo funcionamiento de los territorios, a través de aquello que denomino horizontalidades y verticalidades. Las horizontalidades serían los dominios de la contigüidad, de aquellos lugares vecinos reunidos por una continuidad territorial, mientras que las verticalidades estarían conformadas por puntos distantes unos de otros, vinculados por todas las formas y procesos sociales. (...)

El territorio, hoy, puede estar formado por lugares contiguos o por lugares en red. Son, todavía, los mismos lugares que forman redes y que forman el espacio trivial. Son los mismos lugares, los mismos puntos, pero conteniendo simultáneamente funcionalizaciones diferentes, quizás divergentes u opuestas." (Santos, 2002, p. 139; traducción libre del autor).

En la obra colectiva Território, territórios, otro gran geógrafo brasileño, Rogério Haesbert, explora críticamente diversos abordajes disciplinarios e interdisciplinarios del territorio, y en lo referente a su naturaleza relacional, asociada a redes sociales, subraya la historicidad de las relaciones sociales que sustentan los territorios y las territorialidades, plantea:

Podemos afirmar que el territorio es relacional no sólo en el sentido de incorporar un conjunto de relaciones sociales sino también en el sentido (...) de involucrar una relación compleja entre procesos sociales y espacio material. (...)

Ya sea como elemento separado del territorio y que lo domina, o como elemento constitutivo que adquiere una nueva relevancia, la red se sitúa como un referencial teórico fundamental en este debate. Ella es el vehículo por excelencia de la mayor fluidez que alcanza el espacio y, desde nuestro punto de vista, el componente más importante de la territorialidad contemporánea. (Haesbert, 2007, p. 58)

Otro aporte conceptual relevante de este geógrafo brasileño fue el concepto de multiterritorialidad, elaborado primero en un libro de principio de siglo del cual existe versión en castellano (Haesbert, 2011) y luego en un artículo ampliamente difundido, en el cual plantea:

La multiterritorialidad es la posibilidad de tener la experiencia simultánea y/o sucesiva de diferentes territorios, reconstruyendo constantemente el propio. Esta posibilidad siempre existió - (esto es importante, pues incluso los hombres más "primitivos" no se atenían a un solo territorio)-, pero nunca en los niveles contemporáneos, especialmente a partir de la llamada compresión del espacio-tiempo. 
Entonces la experiencia simultánea y/o sucesiva de diferentes territorios define la multiterritorialidad. Yo propongo también distinguir un sentido más amplio y otro más estricto —más contemporáneo, digámoslo así— de la multiterritorialidad.

En un sentido más amplio, la multiterritorialidad se forja en la modernidad especialmente a través de esos dos poderes que, inspirados en Foucault, denominamos poder soberano y poder disciplinario, tanto de modo simultáneo como sucesivo. De modo simultáneo cuando se trata simplemente de la conjugación in situ (en el mismo local) de niveles macro y micro, como la lógica estatal que incluye al mismo tiempo un territorio individual (la propiedad privada), uno municipal, uno estadual o provincial y otro nacional. Los distintos espacios disciplinarios individuales también pueden configurar una multiterritorialidad sucesiva, cuando se pasa, por ejemplo, de un microterritorio disciplinar a otro - del cuarto de la casa a la escuela o de la escuela a la fábrica - Este carácter sucesivo de la multiterritorialidad implica la conjugación, por movilidad, de diferentes territorios formando territorios-red (...). (Haesbert, 2013, pp. 34-35)

Las conceptualizaciones geográficas brasileñas en torno al territorio han sido influyentes en varios otros países, especialmente sudamericanos, incluyendo Colombia. Así, por ejemplo, la cuestión de la multiterritorialidad se relaciona con la multifuncionalidad y el tránsito de territorios-zona a territorios-red en una propuesta de mirada sistémica del territorio, en el marco de un planteamiento propositivo sobre desarrollo rural con enfoque territorial para la paz en Colombia (Leiva, s.f., tabla 1, p. 139).

El diálogo entre las elaboraciones conceptuales brasileñas y colombianas, como también de otros países latinoamericanos, se expresa asimismo en la denominada Geografía Crítica, con el surgimiento de la red GeoRaizAl (Red de Geografía Crítica de Raíz Latinoamericana) y en seminarios internacionales como el de "Geografía Crítica: Territorialidad, Espacio y Poder en América Latina" (Universidad Nacional de Colombia y Universidad Externado de Colombia, 2011).

Una perspectiva centroamericana enriquecedora por su integralidad y por su perspectiva interdisciplinaria, al combinar las dimensiones social, económica, política y cultural del territorio, es la de Mario Sosa, quien plantea la necesidad de partir del reconocimiento de la unidad y complejidad de la realidad, en este caso territorial. El autor constata cómo el estudio del territorio ha transitado desde aproximaciones disciplinarias hasta otras que integran geografía, historia, sociología, antropología 
y ciencia política, entre otros campos de conocimiento. En su aproximación inicial se refiere al territorio como relación geo-eco-antrópica, a su configuración y representación, apropiación y construcción, para luego enfocar al territorio como comprensión de lo "glocal". Se propone -y nos propone- entonces manera de pensar el territorio y luego una definición de éste:

(...) pensar el territorio como una construcción integral, dialéctica, compleja, multidimensional y pluridimensional, desde la vida social y sus múltiples y plurales interrelaciones, procesos y dinámicas, donde lo geográfico y ecológico, lo económico, lo social, lo cultural y lo político fueran entendidos como partes indivisibles y en interacción, lo mismo que sus niveles, ámbitos y escalas.

(...) se concluye definiendo el territorio como un tejido complejo de espacios, lugares y tiempos específicos y circunscritos dinámicamente, que articula una matriz multidimensional de condiciones y circunstancias, de dinámicas y procesos, de sistemas abiertos y duraderos de configuración, representación, reproducción y apropiación de las potencias, energías y elementos objetivos y subjetivos en compleja relación, que funciona como una estructura estructurante de las percepciones, acciones y relaciones de los sujetos y sus actores en la corta y larga duración. El territorio constituye esa compleja red de contenidos y formas, de condicionamientos objetivos y subjetivos interrelacionados, que -consciente o inconscientemente en los diversos actores sociales- estructuran procesos, dinámicas y prácticas sociales. (Sosa, 2012, pp. 2-3, 116-117)

Otra definición general del territorio, desde una perspectiva crítico-geográfica, es la de Mabel Manzanal y Valeria Mosca en el Diccionario del agro latinoamericano: Territorio es la expresión espacial de relaciones de poder entre actores, dirigida a controlar, ocupar e influir en un espacio determinado. Constituye un campo de fuerzas, una red de relaciones múltiples que confluye en la producción social del espacio, la cual se concreta por y a través de relaciones de poder. Esta definición parte de un marco conceptual crítico respecto al funcionamiento del sistema económico, sin desconocer que existen otros múltiples significados, según los marcos cognitivos y epistemológicos desde donde se enuncia (vinculados con la naturaleza, el espacio, la cultura, las identidades, el control social, estatal, etc.). (en Salomón y Muzlera, eds., 2021, p. 1003)

En esta misma obra, Carlos Reboratti ofrece la siguiente definición de territorio rural, un tanto circular por la doble referencia a ruralidad:

Más allá de la polisemia de los términos que lo componen, territorio rural alude básicamente a una porción del planeta delimitada y apropiada por sujetos que forman 
parte de una población rural (menor de 2000 habitantes), los cuales ejercen sobre él diferentes formas de poder e identificación, concretas o virtuales. Dista de ser homogéneo y su construcción es producto de la acumulación histórica de huellas concretas de la sociedad sobre el ámbito natural, que se traducen en distintas formas de organización territorial. (en Salomón y Muzlera, eds., 2021, p. 1009)

Para una visión de conjunto sobre los aportes a la conceptualización del territorio en las ciencias sociales latinoamericanas, desde una lectura epistemológica, con una referencia final a la Geografía, pueden consultarse entre otros el trabajo de Mardones (2014). Este autor indaga sobre la enunciación del territorio en la formación discursiva sobre éste, incluyendo su reducción al espacio, las tierras y la localización político-administrativa; el territorio como apropiación del espacio, relacionada a su vez con el ordenamiento territorial; la separación binaria entre el espacio material y el subjetivo; la interdependencia entre sujetos y territorios, las relaciones socioterritoriales y la funcionalidad del territorio como valor de uso; la materialización del territorio imaginado, el despojo territorial y la reivindicación del territorio, y éste como categoría de análisis metodológico y teórico comprensivo en procesos de planificación, implementación o evaluación de acciones de gestión o productivas. En cuanto realidad epistémica, identifica tres lógicas particulares de construcción de los enunciados: posicionando al territorio en un lugar periférico; o dándole centralidad mediante una aproximación simbólica cultural en la apropiación del espacio, o en función de fuentes bibliográficas y recursos semióticos de las ciencias geográficas.

La geografía latinoamericana, en diálogo con la europea y con otros campos de conocimiento, ha enriquecido considerablemente el concepto de territorio usual en las políticas públicas y en las agencias de cooperación -frecuentemente asociado a "recortes espaciales" a determinada escala- en particular mediante la introducción del concepto de territorio-red. Otro aporte relevante ha sido la comprensión de la multiterritorialidad, tanto simultánea como sucesiva.

En cuanto a los territorios rurales, diversos campos disciplinarios e interdisciplinarios aportan elementos para su conceptualización, aunque se observa también, en algunos casos, cierta tendencia a oscilar entre rasgos definitorios de cualquier tipo de territorio, no necesariamente rural, y definiciones un tanto circulares por cuanto asocian los territorios rurales a modos de vida rurales, sin que éstos últimos se definan en sus propios términos. Por otra parte, algunas definiciones de territorio rural se refieren de una u otra manera al proceso de antropización del medio natural, cuyos grados y modalidades pueden ser relevantes para construir categorizaciones rural-urbanas y para diferenciar distintos tipos de ruralidad. 


\section{Aproximaciones conceptuales por parte de redes y centros de investigación y desarrollo}

Ciertas redes latinoamericanas y centros de investigación para el desarrollo y la incidencia en políticas públicas y procesos territoriales han hecho contribuciones significativas a la elaboración conceptual en torno a los territorios rurales y a sus interacciones con los urbanos, como también a sus funciones actuales o potenciales en el desarrollo regional o nacional.

A continuación se exploran algunas elaboraciones en torno al concepto de territorio en ciertas líneas de trabajo del Centro Latinoamericano para el Desarrollo Rural Rimisp (https://www.rimisp.org), que surgió en 1986 como Red Internacional de Métodos de Investigación de Sistemas de Producción y pocos años después incorporó temáticas relacionadas con el desarrollo territorial. Inicialmente centrada principalmente en la región andina, actualmente tiene una proyección latinoamericana, y es una de las redes internacionales más relevantes e influyentes en sus áreas de competencia. Para Rimisp:

El concepto de "territorio" nos permite superar la falsa dicotomía de lo urbano y lo rural. El territorio es un espacio vivo y socialmente construido, que no refleja necesariamente límites geográficos o administrativos, sino que es el producto de las interacciones sociales entre personas, instituciones, empresas y organizaciones, que expresan una identidad y un propósito compartido. ${ }^{7}$

En un trabajo fundamental de dos de los impulsores principales de Rimisp, en 2004, que sentó las bases para elaboraciones posteriores, además de ofrecer una tipología innovadora de territorios por sus procesos y grados de transformación productiva y desarrollo institucional, se planteó que el territorio debe concebirse

(...) no como un espacio físico "objetivamente existente", sino como un conjunto de relaciones sociales que dan origen y a la vez expresan una identidad y un sentido de propósito compartidos por múltiples agentes públicos y privados (aunque dicha construcción implique muchas veces transitar por procesos de conflicto y negociación). Es dicha identidad la que permite dar sentido y contenido a un proyecto de desarrollo de un espacio determinado, a partir de la convergencia de intereses y voluntades. (Schejtman y Berdegué, 2004, p. 29).

7 https://www.rimisp.org/noticia/el-territorio-es-un-espacio-vivo-y-socialmente-construido/, 1 de julio de 2019. 
Cuatro años después, en el marco conceptual y metodológico para investigaciones aplicadas del programa Dinámicas Territoriales Rurales en América Latina, Rimisp ofreció una definición básica (todavía un tanto circular) y otra operativa de territorio rural:

Territorio Rural: Un espacio rural con una identidad construida socialmente (...) Territorio Rural (definición operacional):

-Escala geográfica - (...) un territorio se encuentra entre grandes regiones políticas o económicas (...) y las pequeñas comunidades locales. Generalmente, un territorio incluirá al menos una parte de dos o más municipios.

-Escala a nivel de políticas - un territorio en el programa es de tamaño suficiente como para ser considerado importante por los decisores de políticas; tiene una masa crítica a nivel político, social y económico y de allí la posibilidad de sustentar el desarrollo.

-Identidad - la población local debe reconocer el territorio. En otras palabras, los límites del territorio deben ser evidentes para ella.

-Vínculos con núcleos urbanos - Dado que las relaciones urbano-rurales son elementos fundamentales de nuestro marco conceptual, los territorios en el programa deben incluir uno o más núcleos urbanos importantes. Bajo ciertas circunstancias (p.e., territorios que se encuentren en sectores distantes), los núcleos urbanos no se incluirán físicamente dentro de los límites de la sección interior de un territorio; sin embargo, la identidad del territorio incluye los vínculos entre ambos espacios.

-Diversidad de actores sociales - Considerando las preguntas de investigación, los territorios en el programa deben incluir diferentes actores sociales. Sectores que son altamente homogéneos en términos de su estructura social son de poco interés para el programa.

-Unidades político-administrativas - Los procesos de políticas se ven limitados por la jerarquía de las autoridades políticas y administrativas y las unidades espaciales en las cuales operan. En el programa los límites de los territorios deberán coincidir con las divisiones políticos-administrativos pertinentes. (Rimisp, 2008, Glosario, pp. 1 y 2$)$.

Posteriormente, apoyándose en planteamientos anteriores, mayormente europeos, sobre regiones funcionales en los países de la OCDE, Rimisp elaboró y aplicó en varios países latinoamericanos el concepto de territorios funcionales, entendidos como espacios que contienen una alta frecuencia de interacciones económicas y sociales entre sus habitantes, sus organizaciones y sus empresas. (...)

La funcionalidad del territorio puede constituirse a través de varios mecanismos, incluyendo: mercados laborales, mercados de bienes o servicios, redes sociales, 
identidad étnica o cultural, y, también, organización político-administrativa del estado que crea espacios de servicios públicos. Es decir, un conjunto de localidades pueden ser parte de un mismo territorio funcional, si las personas viven ahí y se desplazan principalmente entre ellas para trabajar, para acceder a servicios públicos y privados, para comprar y vender, o para interactuar con las personas y organizaciones que hacen parte de su red social.

(...) Formalmente definimos un territorio funcional como un conjunto geográficamente continuo de comunas dentro del cual un porcentaje importante de los habitantes se desplazan regularmente para trabajar. (Berdegué y otros, 2011, pp. 8 y 9).

Más recientemente, Rimisp incorporó a su análisis de territorios funcionales las imágenes satelitales de luminosidad nocturna, junto con una definición de aquéllos como "áreas o entidades localizadas con mayor interacción o conexión entre sí que con áreas externas a ellas (...) y con alta frecuencia de interacciones económicas y sociales entre sus habitantes, organizaciones y empresas." (Berdegue y otros, 2017, p. 7; traducción libre del autor).

\section{La perspectiva de los actores territoriales}

Un aspecto de la mayor relevancia y actualidad es el de las maneras culturalmente diferenciadas de pensar o concebir el territorio a partir de las vivencias y cosmovisiones de los pueblos originarios o comunidades afrodescendientes, como también de los movimientos campesinos y de las propias organizaciones de gestión territorial. E igualmente significativas y pertinentes para la comprensión de sus procesos de conformación, sus transformaciones y sus potencialidades son las maneras de ver y entender el territorio de las mujeres y jóvenes rurales, el primero en el contexto de determinadas relaciones de género, y el segundo en el de las relaciones, continuidades y rupturas intergeneracionales.

Se optó por ofrecer aquí, a manera de ejemplo de visiones alternativas a las oficiales o académicas sobre el territorio, algunos elementos de la perspectiva del pueblo garinagu centroamericano -de lengua garífuna, afrocaribeño e indígena por sus raíces históricas y étnicas africanas y antillanas- acerca de su territorio y su territorialidad (ambas en singular o plural), y luego hacer una breve referencias a maneras posibles de abordar la conceptualización del territorio en términos de género e intergeneracionalidad. 
En la propuesta de Territorio Afín Garífuna Centroamericano, presentada por organizaciones garinagu a la Comisión Regional para la Ejecución de la Ecadert, en 2013 y aprobada en su VI Reunión Ordinaria, se refieren a una territorialidad históricamente construida a través de lazos de consanguinidad, parentesco y afinidad cultural en territorios discontinuos en esos cuatro países, y definen el territorio afín propuesto como:

Área marino costera ubicado en el Caribe Centroamericano, que incluye mar, tierra, montañas, lagos y ríos que sirven para el asiento permanente o temporal del Pueblo Garífuna, ejercer sus actividades productivas, sociales, económicas y políticas, dar vida a su identidad cultural y poner en valor sus expresiones culturales, de acuerdo a su cosmovisión, espiritualidad, principios y valores. El territorio Garífuna y su entorno sirve como vínculo primordial para la comunión y comunicación con sus ancestros (por) las presentes y futuras generaciones e implica una relación de respeto y armonía con todos sus elementos (tierra, aire, agua, y fuego) y los seres materiales y espirituales que lo componen y protegen. (ONEGUA, ONECA, MAMUGAH y CORECUGA, 2013, p. 5)

Como pilares de su concepto de territorio se refieren a la identidad y la cultura, a la espiritualidad, y a la persona dentro de una colectividad. Así fue reconocido por la Secretaría Ejecutiva del Consejo Agropecuario Centroamericano:

El Territorio Garífuna y su entorno sirve como vínculo primordial para la comunión y comunicación con sus ancestros, las presentes y futuras generaciones; implica una relación de respeto y armonía con todos sus elementos (tierra, aire, agua, fuego) y los seres materiales y espirituales que lo componen y protegen. (...)

Desde la llegada a tierras centroamericanas el Pueblo Garífuna ha mantenido una permanente e ininterrumpida relación social, económica, política, cultural, espiritual y familiar. (Montero, s.f.)

La construcción social y reconocimiento oficial por una instancia del SICA de la territorialidad transfronteriza garífuna evidencia la viabilidad de convergencias entre conceptos de territorio propios de una nación culturalmente articulada aunque geográficamente dispersa, y el de territorio afín. Este último concepto o tipo de territorio -discontinuo pero articulado por lazos históricos, sociales y culturales, o con problemáticas y potencialidades comunes- se inspiró justamente en la experiencia histórica y actualidad sociocultural garífuna durante el proceso de formulación de la Ecadert, y se plasmó posteriormente en la elaboración, aprobación e implementación de la propuesta antedicha. 
Tanto la cuestión de género como la intergeneracional -usualmente enfocadas en las mujeres y jóvenes rurales- se ha abordado principalmente en términos de equidad e inequidad, de disparidades, brechas o desigualdades, como también del acceso a derechos y oportunidades, a la participación y al empoderamiento. Esto es claramente fundamental, pero convendría también abordar y explorar sistemáticamente las maneras de viviry percibir, pensar y concebir el propio territorio, a partir de las vivencias individuales o grupales de mujeres rurales en distintos contextos socioeconómicos, político-institucionales y socioculturales, y de jóvenes rurales en diversas situaciones locales y nacionales. Al respecto son pertinentes algunas reflexiones recientes, en un estudio panorámico de Cepal, sobre cómo los sistemas de género organizan a los diferentes actores y grupos sociales de modo que ellos desarrollen y ejerzan distintos conocimientos, labores, prácticas, activos, responsabilidades, habilidades, redes y formas organizacionales en el territorio, determinando a priori las esferas de acción de hombres y mujeres.

(...) El lugar donde viven influye positiva y negativamente en las brechas y restricciones a las que se enfrentan los jóvenes rurales para desplegar su potencial. Las características del territorio ofrecen oportunidades laborales diferenciadas, espacios organizacionales y comunitarios diversos y entramados institucionales particulares, entre otros. (Fernández y otros, 2019, p. 40).

Si los territorios son relacionales y vivenciales, y las experiencias tanto de mujeres como de jóvenes rurales están marcadas por diferencias como las antedichas, cabe esperar que sus conceptos de territorio sean también distintos y diversos, al igual que sus comprensiones de los procesos sociales de construcción de territorialidades donde nacieron y crecieron, sus interpretaciones de la realidad actual de los territorios rurales, urbanos o rural-urbanos en los cuales viven, trabajan, estudian o luchan, y sus visiones o proyectos de futuro, sueños o esperanzas para el porvenir de sus territorios.

\section{Elementos para una conceptualización común y diferenciada de los territorios en América Latina}

Un reciente balance general del autor, a partir de la contrastación de aprendizajes en torno al concepto de territorio en Brasil, Colombia y Centroamérica, propuso un conjunto de conclusiones interpretativas y propositivas que no es posible ni pertinente enumerar aquí, pero que son un punto de partida para otras consideraciones generales sobre las maneras de concebir los territorios en general y los territorios rurales en particular en nuestra América Latina (Samper, 2021, pp. 80-86). Y en otro trabajo 
realizado en el marco de un proyecto de la Comisión Económica para América Latina (Cepal) entre 2020 y 2021, se formularon las siguientes propuestas de definición de territorio/s en general y de territorio/s rural/es, urbano/s y rural-urbano/s.

De manera general, los territorios pueden considerarse como sistemas sociogeográficos complejos y heterogéneos, abiertos, dinámicos y multiescalares, conformados históricamente por las interacciones entre grupos humanos asentados en determinados lugares, e interacciones coevolutivas con un entorno natural progresivamente artificializado. Dichos procesos generan modos y medios de vida particulares, formas de apropiación y de producción específicas, así como determinadas redes sociales y relaciones de poder, e identidades culturales y sentidos de pertenencia. Los territorios se constituyen plenamente como tales mediante procesos de gobernanza relacional, negociación y concertación entre actores sociales, privados e institucionales, y la construcción de un proyecto de futuro consensuado, una estrategia de desarrollo a largo plazo y acciones colectivas sostenidas para su concretización. (Samper y otros, 2021).

La especificidad conceptual de los territorios rurales guarda relación con la relevancia especial de la relación sociedad-naturaleza en ellos, de manera que los modos de vida tienden a estar asociados directa o indirectamente a su acervo de recursos naturales. Esto incluye actividades extractivas, agropecuarias o forestales, con sus cadenas locales de transporte y acopio, procesamiento y distribución, así como actividades de apoyo a las mismas y de aprovechamiento de la biodiversidad y riqueza paisajística del territorio, como las diversas modalidades de turismo rural, y la prestación de servicios ambientales a las ciudades y al conjunto de la sociedad. Son sistemas socionaturales en constante cambio, con elementos ambientales y sociales entrelazados, cuyas características varían considerablemente de un lugar a otro, y de un período al siguiente.

Las gradaciones entre territorios rurales, rural-urbanos y urbanos están asociadas a los procesos de antropización del medio natural, desde el bosque primario o la pradera original, modificados primero muy gradualmente y luego en forma cada vez más acelerada, con la extracción y posterior domesticación de especies vegetales o animales; con la conversión de ecosistemas silvestres en agroecosistemas, y la subsiguiente intensificación, especialización y tecnificación de sistemas de cultivo y cría, hasta la transformación completa de la cobertura del suelo por actividades constructivas a menor o mayor escala y la densificación del poblamiento. A lo largo del gradiente rural-urbano se entremezclan campo y ciudad tanto espacial como 
funcionalmente, con flujos e intercambios de energía y de bienes, de personas y de trabajo, de conocimientos e información.

La ruralidad y las interacciones rural-urbanas tienen expresiones diferentes a diversas escalas, y los territorios pueden ser locales, asociados a comunidades, municipios o paisajes; pueden ser microrregiones conformadas por un conjunto de municipios, por una subcuenca o por rasgos identitarios socioambientales, socioeconómicos o socioculturales; mesorregiones o subregiones con centros poblados y con sistemas de producción agropecuarios localizados o con diversas modalidades de aprovechamiento de los recursos naturales del lugar, o regiones mayores, relacionadas con sistemas agrarios complejos que engloban múltiples sistemas de producción y formas de apropiación de la tierra y del trabajo, o con territorios funcionales conformados por ciudades principales o intermedias y zonas rurales próximas o distantes articuladas con ellas.

Pero los territorios no son necesariamente continuos en su espacialidad, sino que pueden estar constituidos por un conjunto de territorios menores con afinidades ecológicas o económicas, interconexiones sociopolíticas o identidades socioculturales compartidas, con una historia y una cosmovisión comunes. Tampoco están necesariamente demarcados o nítidamente delimitados, sino que pueden superponerse unos con otros, o tener límites difusos y variables; pueden incluso ser geográficamente móviles, como cuando comunidades enteras se desplazan forzosa o voluntariamente a otro lugar, donde reconstruyen su tejido social y sus modalidades de relación con la naturaleza. Y si las relaciones sociales siempre fueron cruciales en la construcción de territorios y territorialidades, cada vez más tienden a deslocalizarse, de manera que se conforman territorios-red que no tienen un referente espacial único sino varios o ninguno, y adquieren una fluidez inusitada, plena de complejidades y de potencialidades.

\section{BIBLIOGRAFÍA}

APFP (Association de Promotion et de Féderation des Pays). (2012). Les Pays, moteurs de stratégies de développement territorial et de gouvernance locale. En: Les États Généreaux de la Démocratie Territoriale, consulta a representantes electos locales organizada por el Senado de Francia. Disponible en http://www.senat.fr/ democratie-territoriale.html, consultado el 7 de junio de 2021.

Asamblea Nacional Constituyente, Colombia. (1991). Constitución Política de 
Colombia.

Asamblea Legislativa de la República de Costa Rica.(2012). Ley 9036. Transformación del Instituto de Desarrollo Agrario (IDA) en el Instituto de Desarrollo Rural (Inder). Publicada en La Gaceta, no. 103, 29 de mayo de 2012.

Becattini, G. (2002). Del distrito industrial marshalliano a la «teoría del distrito» contemporánea. Una breve reconstrucción crítica. En Investigaciones Regionales Journal of Regional Research [en linea], Asociación Española de Ciencia Regional, 2002 (1), pp. 9-32. Disponible en https://www.redalyc.org/articulo.oa?id=28900101, consultado el 1 de junio de 2021.

Berdegué, J.; Jara, B.; Fuentealba, R.; Tohá, J.; Modrego, F.; Schejtman, A. y Bro, N. 2011. Territorios Funcionales en Chile. Documento de Trabajo N ${ }^{\circ} 102$. Programa Dinámicas Territoriales Rurales. Santiago, Chile: Rimisp. Disponible en: https://www.rimisp.org/wp-content/files_mf/files_mf/1366288203N1022011 TerritoriosFuncionalesChile_BerdegueJaraFuentealbaTohaetal.pdf, consultado el 1 de julio de 2021.

Berdegué, J.; Hiller, T.; Ramírez, J.M.; Satizábal, S.; Soloaga, I.; Soto, J.; Uribe, M.; Vargas, M. (2017). Delineating funcional territories from outer space. Working Paper Series no. 230. Territorial Cohesion Development Group. Santiago de Chile: Rimisp. Disponible en: https://rimisp.org/wp-content/files_mf/1516719140DTDELINEATIN GFUNCTIONALTERRITORIESFROMOUTERSPACE.pdf, consultado el 2 de julio de 2021.

Berdegué, J.; Favareto, A. (2019). Desarrollo Territorial Rural en América Latina y el Caribe. 2030 - Alimentación, agricultura y desarrollo rural en América Latina y el Caribe, No. 32. Santiago de Chile. FAO. Disponible en: http://www.fao.org/3/ ca5059es/ca5059es.pdf, consultado el 10 de julio de 2021.

Boix, R. (2008). Los distritos industriales en la Europa Mediterránea: los mapas de Italia y España. En Soler, V. (coord.), Los distritos industriales. Colección Mediterráneo Económico, núm. 13. Almería: Fundación Cajamar. Disponible en https://www. publicacionescajamar.es/publicacionescajamar/public/pdf/publicaciones-periodicas/ mediterraneo-economico/13/13-218.pdf, consultado el 1 de junio de 2021.

Bonnal, P.; Maluf, S. (2009). Políticas de desenvolvimento territorial e multifuncionalidade da agricultura familiar no Brasil. En: Política \& Sociedad, no. 14, abril de 2009, pp. 212-250. Disponible en: https://www.researchgate. net/publication/267715711_Politicas_de_desenvolvimento_territorial_e_ 
multifuncionalidade_da_agricultura_familiar_no_Brasil, consultado el 15 de julio de 2021

Brito, CC. (2017). Conceito de território rural e políticas públicas e sua evolução histórica nos governos FHC e Lula. En: Cadernos Gestão Pública e Cidadania, São Paulo, v. 22, n. 72, mayo/ago. 2017, 173-192. Disponible en: https://bibliotecadigital. fgv.br/ojs/index.php/cgpc/article/view/60260, consultado el 7 de agosto de 2021.

Brunelli, P. (2014). Evoluzione del distretto industriale. Serie Sistemi e modelli economici. Edi\&Sons Edizioni. Consultado en https://www.scribd.com/ book/315136710/Evoluzione-del-Distretto-Industriale-L-industria-alla-sfida-delventunesimo-secolo el 1 de junio de 2021.

Caballero, J.M.; de la Cuesta, J.M.; Prieto, T. (2011). Estudio sobre la aplicación del enfoque LEADER en las Comunidades Autónomas. Burgos: Universidad de Burgos y Red de Desarrollo Rural.

CAC (Consejo Agropecuario Centroamericano). (2010). Estrategia Centroamericana de Desarrollo Rural Territorial 2010 - 2030 • ECADERT. San José: CAC.

Capel, H. (2016). Las ciencias sociales y el estudio del territorio. Biblio3W Revista Bibliográfica de Geografía y Ciencias Sociales. [En línea] Barcelona: Universidad de Barcelona. Vol. XXI, núm. 1, https://revistes.ub.edu/index.php/b3w/article/ view/26319, consultado el 10 de julio de 2021.

Cepal (Comisión Económica para América Latina). (2010). La hora de la igualdad. Brechas por cerrar, caminos por abrir. 33er período de sesiones de la Cepal. Brasilia, 30 de mayo a 1 de junio de 2010. Santtiago de Chile: Cepal. Disponible en: https:// www.cepal.org/es/publicaciones/13309-la-hora-la-igualdad-brechas-cerrar-caminosabrir-trigesimo-tercer-periodo, consultado el 20 de julio de 2021.

Cepal (Comisión Económica para América Latina). (2019). Planificación para el desarrollo territorial sostenible en América Latina y el Caribe. [LC/CRP.17/3] Santiago de Chile: Cepal. Disponible en: https://www.cepal.org/es/publicaciones/44731planificacion-desarrollo-territorial-sostenible-america-latina-caribe, consultado el 20 de julio de 2021.

Comisión Europea. (1988). El futuro del mundo rural. Comunicación de la Comisión al Parlamento Europeo y al Consejo. Boletín de las Comunidades Europeas, suplemento 4/88. Comisión de las Comunidades Europeas. Disponible en: http://repositori.uji.es/ xmlui/bitstream/handle/10234/48437/Suplemento4-88..pdf?sequence=1, consultado 
el 31 de julio de 2021.

CAN (Comunidad Andina de Naciones). (2013). Lineamientos y objetivos estratégicos de desarrollo rural territorial de la Comunidad Andina. Documentos de Trabajo, Secretaría General de la Comunidad Andina. SG/CMA/IV/dt4, 26 de junio de 2013, A.2. IV Reunión del Consejo de Ministros de Agricultura de la Comunidad Andina. Lima: Secretaría General de la Comunidad Andina.

Congreso Mexicano (Congreso de la Unión, Estados Unidos Mexicanos). (2001). Ley de Desarrollo Rural Sustentable. Publicada en el Diario Oficial de la Federación el 7 de diciembre de 2001.

Da Rocha, M.R..T; Filippi, E.E. (s.f.). Política para o desenvolvimento dos territórios rurais no Brasil: propostas e fundamentos. Disponible en: http://www. ufrgs.br/pgdr/publicacoes/producaotextual/eduardo-ernesto-filippi/teixeira-darocha-maria-r-filippi-e-e-politica-para-o-desenvolvimento-dos-territorios-ruraisno-brasil-propostas-e-fundamentos-in-vi-seminario-internacional-de-desarrollorural-configuraciones-de-los-territorios-rurales-en-el-siglo-xxi-2007-bogota-anales, consultado el 10 de agosto de 2021-

De los Ríos-Carmenado, I.; Díaz-Puente, J.M.; Cadena-Iñiguez, J. (2011). La iniciativa LEADER como modelo de desarrollo rural: Aplicación a algunos territorios de México. En: Agrociencia, 1 de julio a 15 de agosto de 2011, pp. 609624. Disponible en: http://www.scielo.org.mx/scielo.php?script=sci_arttext\&pid $=$ S1405-31952011000500007, consultado el 3 de agosto de 2021.

DNP (Departamento Nacional de Planeación, Colombia), Comité Especial Interinstitucional, Comité Técnico Intersectorial de Asociatividad Territorial. (2013). Definición legal y funcional de los esquemas asociativos de entidades territoriales en Colombia. Bogotá: DNP.

Doré, G. (2011). Le Pays, un singulier pluriel. En: Pour, La revue du Groupe Ruralités, Éducation et Politiques, 2011/2-3 ( $\left.\mathrm{N}^{\circ} 209-210\right)$, pp. 89-102. Disponible en https://www.cairn.info/revue-pour-2011-2-page-89.htm, consultado el 7 de junio de 2021.

Doré, G. (2017). Le retour de l'Etat français dans la contractualisation avec les territoires en France : La politique des Contrats de ruralité. En 11es Journées de Recherches en Sciences Sociales JRSS 2017, Lyon, 14-15 de diciembre de 2017. Disponible en https://www.sfer.asso.fr/source/jrss2017/jrss2017-article-dore.pdf, consultado el 7 de junio de 2021. 
Esparcia, J.; Noguera, J. (1999). Reflexiones en torno al territorio y al desarrollo rural. En: Ramos, E. (coord.) (1999). El desarrollo rural en la Agenda 2000. Madrid: Ministerio de Agricultura, Pesca y Alimentación. Disponible en https://www.mapa. gob.es/ministerio/pags/Biblioteca/fondo/pdf/25132_all.pdf, consultado el 7 de junio de 2021.

Esparcia, J.; Mesa, R. (2020). LEADER en España. Cambios recientes, situación actual y orientaciones para su mejora. Valencia: Univsersitad de València. Dispo nible en: https://www.age-geografia.es/site/wp-content/uploads/2020/09/LEADERen-Espana-EBOOK-J-Esparcia-R-Mesa.pdf, consultado el 8 de junio de 2021.

Favareto, A. 2009. Retrato das políticas de desenvolvimento territorial no Brasil. Documento de Trabajo No 26 Programa Dinámicas Territoriales Rurales Rimisp Centro Latinoamericano para el Desarrollo Rural. Disponible en: https://www.rimisp. org/documentos/retrato-das-politicas-de-desenvolvimento-territorial-no-brasil-2/, consultado el 1 de agosto de 2021.

Fernánez, J; Fernández, M.I.; Soloaga, I. (2019). Enfoque territorial y análisis dinámico de la ruralidad: alcances y limites para el diseño de políticas de desarrollo rural innovadoras en América Latina y el Caribe. Documentos de proyectos. México, D.F.: Cepal.

Ghesti, J.P. (2014). A disseminação de Políticas de Desenvolvimento Territorial Rural na América Latina: um estudo comparado entre Brasil e Argentina. Tesis de Maestría, Desenvolvimento, Globalização e Regionalização, Centro de Pesquisa e Pós-graduação sobre as Américas, Universidad de Brasília. Disponible en: https:// repositorio.unb.br/handle/10482/17036, consultado el 19 de julio de 2021.

Haesbert, R. (2007). Concepções de território para entender a desterritorialização. En: Santos, M.; Becker, B.K. (org.). (2007) . Território, territórios. Ensaios sobre o ordenamento territorial. $3^{\text {a }}$. Edición. Libro escaneado disponible en: https:// facilitageo.com/wp-content/uploads/2021/07/Territorio-territorios-Ensaios-sobreo-ordenamento-territorial.pdf; visualizable en línea: https:/es.slideshare.net/ CarvalhoFilipes/santos-milton-becker-bertha-k-org-territrio-territrios-ensaios-sobreo-ordenamento-territorial, consultado el 10 de agosto de 2021.

Haesbaert, R. (2011). El Mito de la Desterritorialización, del fin de los territorios a la multiterritorialidad. México: Siglo XXI. Editores.

Haesbaert, R. (2013). Del mito de la desterritorialización a la multiterritorialidad. En: Cultura y Representaciones Sociales, Año 8, no. 15, septiembre de 2013, pp. 9 a 42. 
Disponible en: http://www.scielo.org.mx/pdf/crs/v8n15/v8n15a1.pdf, consultado el 13 de julio de 2021.

IICA (Instituto Interamericano de Cooperación para la Agricultura). (2006). Políticas para la prosperidad rural. La contribución de la agricultura y de los territorios rurales a la creación de empleo y la reducción de la pobreza. San José: IICA. Disponible en: http://repositorio.iica.int/handle/11324/7651, consultado el 1 de junio de 2021.

JICA (Agencia de Cooperación Internacional de Japón). (2012). Estudio de casos sobre el desarrollo de los territorios rurales en América Latina y el Caribe. Informe final. Asunción: JICA. Disponible en: https://www.jica.go.jp/paraguay/espanol/ office/others/c8h0vm0000ad5gke-att/info_05.pdf, consultado el 10 de junio de 2021. Leiva, F. (s.f.). Desarrollo rural con enfoque territorial para la paz en Colombia. Bogotá: Centro de Pensamiento en Desarrollo Rural, Universidad Nacional de Colombia. Disponible en: http://pensamiento.unal.edu.co/fileadmin/recursos/ focos/2016_Politica_Enfoque_Territorial_CP_Dllo_Rural.pdf, consultado el $11 \mathrm{de}$ agosto de 2021 .

Lollier, J-C. (1999). La experiencia de la política PAYS en Francia. En Ramos, E. (coord.) (1999). El desarrollo rural en la Agenda 2000. Madrid: Ministerio de Agricultura, Pesca y Alimentación. Disponible en https:/www.mapa.gob.es/ ministerio/pags/Biblioteca/fondo/pdf/25132_all.pdf, consultado el 7 de junio de 2021.

Llanos-Hernández, L. (2010). El concepto del territorio y la investigación en las ciencias sociales. En: Agricultura, sociedad y desarrollo, 7(3), 207-220. Recuperado en 1 de agosto de 2021, de http://www.scielo.org.mx/scielo.php?script=sci arttext\&pid=S1870-54722010000300001\&lng=es\&tlng=es, consultado el 3 de julio de 2021.

MADR (Ministerio de Agricultura y Desarrollo Rural, Colombia). (2017). Lineamientos estratégicos de política pública. Agricultura Campesina, Familiar y Comunitaria (ACFC). Promulgados por Resolución Ministerial 464 de 2017. Bogotá: MADR , Mesa Técnica de Agricultura Familiar y Economía Campesina, y Unión Europea. Disponible en: http://agriculturafamiliar.co/mesa-tecnica/lineamientosestrategicos-de-politica-publica-para-la-agricultura-campesina-familiar-ycomunitaria/, consultado el 15 de mayo de 2021.

MAG (Ministerio de Agricultura y Ganadería, Costa Rica). (2011). Política de Estado para el Sector Agroalimentario y el Desarrollo Rural Costarricense 20102021. San José: MAG. Disponible en: http://sepsa.go.cr/docs/2011_Politica_ 
SectorAgro_2010-2021.pdf, consultado el 9 de agosto de 2011.

Mardones, R. (2014). Epistemología del territorio. Naturaleza de la enunciación del conocimiento del Territorio en la producción científica latinoamericana en ciencias sociales. Tesis presentada en la Universidad de La Frontera para optar al Grado de Magister en Ciencias Sociales Aplicadas. Temuco, Chile: Universidad de la Frontera. Disponible en: http://magistercienciassociales.ufro.cl/wp-content/uploads/2018/11/ MARDONES-Rodolfo-1.pdf, consultado el 3 de agosto de 2021.

MAPA (Ministerio de Agricultura, Pesca y Alimentación, España). (2003) El libro Blanco de la Agricultura y el Desarrollo Rural. Tomo I. Madrid: MAPA. Disponible en: https://www.mapa.gob.es/es/ministerio/servicios/informacion/plataforma-deconocimiento-para-el-medio-rural-y-pesquero/biblioteca-virtual/libros-blancos/ agricultura-t1.aspx, consultado el 6 de agosto de 2021.

Montero, R. (s.f.). Territorios afines en el marco de la ECADERT: El rol de los pueblos afrodescendientes en el desarrollo rural de la región. [Presentación en Powerpoint] Secretaría Ejecutiva del Consejo Agropecuario Centroamericano.

Moyano, P.B.; Miranda, B.; Gordo, P. (2017). La participación de los agentes económicos y sociales en la revitalización de los municipios rurales. En: Investigaciones Regionales - Journal of Regional Research, 38 (2017), pp. 91-115. Disponible en: https://dialnet.unirioja.es/servlet/articulo? codigo $=6194964$, consultado el 8 de junio de 2021.

ONEGUA (Organización Negra Guatemalteca), ONECA (Organización Negra de Centroamérica), MAMUGAH(Mancomunidadde Municipios Garífunas de Honduras) y CORECUGA (Comité de Revitalización de la Cultura Garífuna en Nicaragua). (2013). Bases para la Propuesta de Territorio Afín Garífuna Centroamericano. Estrategia centroamericana de Desarrollo Rural Territorial -ECADERT. Presentada ante la Comisión Regional para la Ejecución de la Ecadert y aprobada en su VI Reunión Ordinaria el 19 de julio de 2013.

Paquot, T. (2012). Qu'est-ce qu'un « territoire »? En : Review Vie Sociale, 2011/12, no. 2, pp. 23-32. Disponible en https://www.cairn.info/revue-vie-sociale-2011-2page-23.htm, consultado el 15 de julio de 2021.

Péaud, L. (2016). Les apports de la philosophie à la pensée géographique de l'espace. En : Géograhpie et Cultures, no. 100, 100 | 2016, puesto en línea el 7 de junio 2018. Disponible en: http://journals.openedition.org/gc/4690, consultado le 3 de agosto de 2021. 
PNUD (Programa de Naciones Unidas para el Desarrollo). (2013). Manual de Desarrollo Económico Territorial. San Salvador: PNUD. Disponible en: https:// www.sv.undp.org/content/el_salvador/es/home/library/poverty/manual-desarrolloeconomico-territorial.html, consultado el 25 de julio de 2021.

Presidencia de la República de Colombia y Estado Mayor Central de las FARCEP (Fuerzas Armadas Revolucionarias de Colombia). (2016). Acuerdo final para la terminación del conflicto y la construcción de una paz estable y duradera. Bogotá. Acuerdo original firmado escaneado disponible en: https://www.jep.gov.co/ Documents/Acuerdo\%20Final/Acuerdo\%20Final\%20Firmado.pdf, consultado el 10 de agosto de 2021. Texto completo del acuerdo disponible en: https://peacemaker. un.org/sites/peacemaker.un.org/files/Colombia $\% 20$ Nuevo $\% 20$ Acuerdo $\% 20$ Final\%2024\%20Nov\%202016_0.pdf, consultado el 10 de agosto de 2021.

Quintar, A.; Gatto, F. (1992). Distritos industriales italianos. Experiencias y aportes para el desarrollo de políticas industriales locales. Documento de Trabajo PRIDRE No. 29. Buenos Aires: Cepal. Disponible en https://repositorio.cepal.org/ handle/11362/9310, consultado el 1 de junio de 2021.

Red Rural Nacional. (s.f.) LEADER en España (1991-2011) Una contribución activa al desarrollo rural. Madrid: MARM (Ministerio de Medio Ambiente y Medio Rural y Marino). Disponible en: https://www.mapa.gob.es/es/desarrollo-rural/publicaciones/ publicaciones-de-desarrollo-rural/INFORME\%20LEADER_tcm30-131208.pdf, consultado el 8 de junio de 2021.

Rey, HA. Aplicación de la metodología LEADER para la selección de territorios en el Valle del Cauca. En: Revista de Economía \& Administración, Vol. 6, No. 2, juliodiciembre de 2009, pp. 93-107. Disponible en: https://revistas.uao.edu.co/ojs/index. php/REYA/article/view/209, consultado el 23 de julio de 2021.

Riffo, L. (2013). 50 años de ILPES: evolución de los marcos conceptuales sobre desarrollo territorial. Serie Desarrollo Territorial, 15. Santiago de Chile: Naciones Unidas. Disponible en: https://www.cepal.org/es/publicaciones/7248-50-anos-ilpesevolucion-marcos-conceptuales-desarrollo-territorial, consultado el 13 de julio de 2021.

Rimisp (Centro Latinoamericano de Desarrollo Rural). (2008). Investigación Aplicada de Dinámicas Territoriales Rurales en América Latina: Marco Metodológico (versión 2). Documento de Trabajo No 2, Programa Dinámicas Territoriales Rurales. Santiago de Chile: Rimisp. Disponible en: https://www.rimisp.org/wp-content/files mf/13663831882008_rimisp_marco_metodologico_version2.pdf, consultado el 10 
de agosto de 2021.

Rosell, J. (2002). Programas de desarrollo rural en la Unión Europea: La iniciativa comunitaria LEADER. En: Perspectivas Rurales Nueva Época, 6, 11-12, noviembre 2002, pp. 33-88. Disponible en: https://www.revistas.una.ac.cr/index.php/ perspectivasrurales/article/view/3581, consultado el 6 de agosto de 2021.

Salomón, A.; Muzlera, J. (2021). Diccionario del agro Iberoamericano: 3ra edición. Ciudad Autónoma de Buenos Aires: Jose Muzlera. [Libro digital, PDF]. Disponible en: https://www.teseopress.com/diccionarioagro/, consultado el 5 de agosto de 2021.

Samper, M.; González, H. (2018 a). Experiencias político-institucionales y territoriales en Colombia. Cuadernos de Trabajo sobre Inclusión, No. 13. San José: IICA. Versión web: http://repositorio.iica.int/bitstream/11324/7234/1/BVE18040323e.pdf

Samper, M.; González, H. (2018 b). Experiencias político-institucionales y territoriales en Brasil, Cuadernos de Trabajo sobre Inclusión, No. 14. San José: IICA. Versión web: http://repositorio.iica.int/bitstream/11324/7235/1/BVE18040324e.pdf

Samper, M. (2019). Desarrollo rural con enfoque territorial en América Central. Perspectiva regional y experiencias nacionales: Aprendizajes. Cuadernos de Trabajo sobre Inclusión, No. 19. San José: IICA. Versión web: http://repositorio.iica.int/ bitstream/handle/11324/17747/BVE21078201e.pdf?sequence=1\&isAllowed=y

Samper, M. (2020). Aprendizajes de experiencias latinoamericanas en gestión social del desarrollo territorial: Reflexiones e implicaciones conceptuales, metodológicas y político-institucionales. Cuadernos de Trabajo sobre Inclusión no. 20, diciembre de 2020. San José: IICA. Versión web: http://repositorio.iica.int/bitstream/ handle/11324/17452/BVE21068778e.pdf?sequence=1\&isAllowed=y

Samper, M.; Martínez, M.; González, H. (2021). Medición y caracterización de los espacios rurales en Costa Rica a partir de estadísticas nacionales: Elementos conceptuales, metodología aplicada y resultados principales. Informe principal del proyecto Nuevas narrativas para la transformación rural en América Latina y el Caribe, de Cepal y FIDA. En proceso de publicación en la serie Documentos de Proyecto, de la Oficina Subregional de Cepal en México.

Santos, M. (1999). Metamorfosis del espacio habitado. Barcelona: Editorial OikosTau.

Santos, M. (2000). El território: um agregado de espacios banales. En: Boletín de Estudios Geográficos, No 96, pp. 87-96. Disponible en: https://dialnet.unirioja.es/ 
servlet/articulo?codigo=1165747, consultado el 20 de julio de 2021.

Santos, M. (2002). O retorno do território. En: Santos, M. (2002). Da totalidade ao Lugar. São Paulo: Editora da Universidade de São Paulo, pp. 137-144.

Sarraceno, E. (2007). Políticas rurales de la Unión Europea y proyectos territoriales de identidad cultural. En: Revista Opera, Universidad Externado de Colombia, No. 7, pp. 167-189. Disponible en: https://dialnet.unirioja.es/servlet/articulo?codigo=4020440, consultado el 1 de julio de 2021.

Schejtman, A.; Berdegué, J. (2004). Desarrollo territorial rural. Debates y Temas Rurales no. 1. Santiago de Chile: Rimisp. Disponible en: https://www.rimisp.org/wpcontent/files_mf/1363093392schejtman_y_berdegue2004_desarrollo_territorial_ rural_5_rimisp_CArdumen.pdf, consultado el 15 de julio de 2021.

Sepsa (Secretaría Ejecutiva de Planificación Sectorial Agropecuaria, Costa Rica) e Inder (Instituto de Desarrollo Rural). (2016). Política de Estado para el Desarrollo Rural Territorial Costarricense (PEDRT) 2015-2030. San José: Sepsa e Inder. Disponible en: http://www.sepsa.go.cr/PRODUCTOS/2016-APAR_PEDRT\%20 2015-2030.pdf, consultado el 10 de agosto de 2021.

Sforzi, F. (1990). The quantitative importance of Marshallian industrial districts in the Italian economy; en Pyke, F..; Becattini, G. y Sengenberger, W., eds., Industrial Districts and Inter-firm co-operation in Italy. Ginebra: OIT. Disponible en https:// www.researchgate.net/publication/262564260_The_quantitative_importance_of_ Marshallian_industrial_districts_in_the_Italian_economy, consultado el 7 de junio de 2021.

Soberanes, M. y Burgin, M.J. (2009). Catastro de políticas y programas de desarrollo territorial rural en México. Documento de Trabajo no. 28. Programa Dinámicas Territoriales Rurales. Santiago de Chile: Rimisp. Disponible en: https://www.rimisp. org/documentos/catastro-de-politicas-y-programas-de-desarrollo-territorial-rural-enmexico-2/, consultado el 3 de agosto de 2021.

Sosa, M. (2012). ¿Cómo entender el território? Guatemala: Editorial Cara Parens. Disponible en: https://www.rebelion.org/docs/166508.pdf, consultado el 10 de julio de 2021.

Sposito, E; Saquet, M. (2016). O conceito de território no Brasil: entre o urbano e o rural. En: Caderno Prudentino de Geografia, Presidente Prudente, n.38, v.2, p.84112, ago./dic. 2016. Disponible en: https://revista.fct.unesp.br/index.php/cpg/article/ 
view/5502, consultado el 5 de agosto de 2021.

Sumpsi, JA. (2006 a). Experiencias Piloto de Desarrollo Local Rural en América Latina: Lecciones del Proyecto EXPIDER en Bolivia, Ecuador y Honduras. Publicación del Banco Interamericano de Desarrollo (BID) No. RUR-06-02. Washington: BID. Disponible en: https://publications.iadb.org/es/experiencias-piloto-de-desarrollolocal-rural-en-america-latina-lecciones-del-proyecto-expider-en, consultado el 26 de julio de 2021.

Sumpsi, JA. (2006 b). Experiencias de desarrollo rural con enfoque territorial en la Unión Europea y América Latina. En: Estudios Agrosociales y Pesqueros, no. 2019, pp. 41-71. Disponible en : https://dialnet.unirioja.es/servlet/articulo?codigo=2307965, consultado el 28 de julio de 2021.

Universidad Nacional de Colombia, Universidad Externado de Colombia. (2011). Memorias. Seminario Geografía Crítica: Territorialidad, Espacio y Poder en América Latina. Bogotá: Universidad Nacional y Universidad Externado de Colombia. Disponible en: https://repositorio.unal.edu.co/handle/unal/9307, consultado el 11 de agosto de 2021.

Vanier, M. (2016). Réforme territoriale et espace rural. En: Pour, La revue du Groupe Ruralités, Éducation et Politiques, 2015/4 ( ${ }^{\circ}$ 228), pp. 147-153. Disponible en https://www.cairn.info/revue-pour-2015-4-page-147.htm, consultado el 7 de junio de 2021. 